\title{
Translating Proper Nouns: A Case Study on English Translation of Hafez's Lyrics
}

\author{
Seyed Alireza Shirinzadeh ${ }^{1} \&$ Tengku Sepora Tengku Mahadi ${ }^{1}$ \\ ${ }^{1}$ School of Languages, Literacies \& Translation, Universiti Sains Malaysia, Malaysia \\ Correspondence: Seyed Alireza Shirinzadeh, Faculty of Translation Studies, School of Languages, Literacies \& \\ Translation, Universiti Sains Malaysia, 11800, Penang, Malaysia. E-mail: alireza.shirinzadeh@gmail.com
}

Received: April 29, 2014 Accepted: May 29, 2014 Online Published: June 13, 2014

doi:10.5539/elt.v7n7p8 URL: http://dx.doi.org/10.5539/elt.v7n7p8

\begin{abstract}
Proper nouns are regarded so simple that they might be taken for granted in translation explorations. Some may believe that they should not be translated in transmitting source texts to target texts. But, it is not the case; if one looks at present translations, he will notice that different strategies might be applied for translating proper nouns. They might often be problematic in translation especially in the course of rendition between different cultures. Thus, they are worth exploring. The present study aims to investigate the strategies that have been used in rendering proper nouns by Pazargadi (2003) in his English translation of Hafez's lyrics. For this purpose, Vermes' (2003) model of translation strategies for rendering proper nouns has been adapted by the researchers in the study. It has been revealed that the translator has used the transference strategy most preferably for rendering proper nouns of Hafez's lyrics into English.
\end{abstract}

Keywords: translation strategy, proper noun, Hafez's lyrics, Vermes' model

\section{Introduction}

Rendering proper nouns is not certainly a simple task as it can be problematic in the act of translation (Sanaty Pour, 2009); furthermore, translators have to be very careful when they want to translate proper nouns. Previous literature indicates that various translation strategies have been used in the course of translation. Accordingly, Vermes (2003, pp. 89-90) states that:

The translation of proper names has often been considered as a simple automatic process of transference from one language into another, due to the view that proper names are mere labels used to identify a person or a thing. (...) the translation of proper names is not a trivial issue but, on the contrary, may involve a rather delicate decision-making process, requiring on the part of the translator careful consideration of the meanings the name has before deciding how best to render it in the target language.

In line with him, Newmark (1993, p. 15) believes that proper nouns are "a translation difficulty in any text". For example, in literary texts it should "be determined whether the name is real or invented. In nonliterary texts, translators have to ask themselves what if any additional explanatory or classificatory information has to be supplied for the TL readership".

Every language has specific proper nouns, some of them are completely related to the culture of the people of that particular language (Sanaty Pour, 2009). Accordingly, these nouns can bring about special understanding problems for the readers of that text. Proper nouns may have particular implications and removing the hidden connotations leads to a translation which is not acceptable. In line with this, Bachman (1990) states that knowing just the referential meaning of the nouns without the knowledge of the implications and connotations of the nouns will result in inaccurate translation of the nouns. Therefore, knowing figurative language and cultural references along with the referential meaning is an important factor.

Translating or preserving or transferring of the proper nouns depends on the nature of the languages at hand. Whether the source and target languages are from the same family or whether the proper name is a trans-cultural name, i.e., it is used in other languages or due to two totally different cultures the nouns are also different; In fact, all the aforementioned issues affect the strategy that the translator may want to use. He may simply translate it or transfer it or do some changes on it in the target language, changes such as phonological ones so as to match it with the target language natural phonological system. All of them should be considered in the process of 
translation. This shows the importance of rendering a name that may appear so simple in the course of translation and that it might be taken for granted. The text type also plays an important role here. Whether the text is literary or nonliterary, scientific perhaps. Whether it belongs to the domain of children literature or it is not, but it should be translated for the children readers; and many other factors can affect the process of translating proper nouns. As a whole, in the act of translation, nouns are nouns but they should be regarded from various angles.

\section{Literature Review}

Culture always plays an important role in all issues of translation and in proper name rendering as well. Accordingly, Hervey and Higgins (2002) believe that translation "involves not just two languages, but a transfer from one whole culture to another" (p. 31). They believe that comparing to linguistic dissimilarities, differences in cultures can cause more difficulties for a good rendition of the source text. Personal names rendition also involves in culture like other aspects of the source texts. Even though personal names are names, sometimes, they may have some connotations or they may be so integrated with culture that cannot be regarded just a name any more. They may look familiar to the source text readers but not to the target text readers. Therefore, translators should know all the issues related to nouns. As a result, translators should be "cultural mediators" (Katan, 1999, p. 1). Accordingly, Hatim and Mason (1990) believe that the issue of biculturality is more important than the issue of bilinguality in translation. Translators are negotiators between two cultures, namely, source and target cultures. They should control the cultural differences that may hinder the process of transferring the meaning.

Hervey and Higgins (2002) insist on the issue of "cultural transposition" and state that proper nouns are directly related to the aforementioned issue (p. 32). Although rendering nouns is not regarded as an important phenomenon, it is integrated with the issue of culture in translation. They believe that translators have two options while rendering nouns. They can either transfer nouns to the target text without any changes, or adapt them to follow the target language phonetic and orthographic conventions. The first option brings into the translation a foreign sense (Venuti, 1998, 2001); a sense which shows that the text at hand is a translation not an original piece of writing. However, not changing the source text nouns in the translation may sometimes bring about problems (Hervey \& Higgins, 2002). They may be hard to be pronounced or spelled or even memorized. Here, the second mentioned option comes on stage, namely, transliteration. Hervey and Higgins state that this strategy can be used for coping with the above-mentioned problems via following the target language rules in using the source text nouns. They further state that transliteration is the normal method of dealing with the Chinese and Russian nouns in English texts. In the case that the ST name has not been transliterated before by others, it is at the hand of the translator to transliterate it; and sometimes, other translators have transliterated it before so the translator can simply use that form. Hervey and Higgins state that normal transliteration is different among languages like "Venezia/Venice/Venise/Venedig, and Salzburg/Salzbourg/Salisburgo" (p. 32). Sometimes, the target language has equivalents for the source text nouns, e.g. "French 'Saint Jean', German 'St Johannes', Italian 'S. Giovanni'”; or "Flemish 'Luik', French 'Liege', German 'Luttich' and Italian 'Liegi”' (p. 32). Normally, translators use the equivalents in the target language; however, there are occasions that the translators may not use the TL equivalent when they intend to bring to mind a foreign sense in the target text so as to make the source text visible in the target one (Venuti, 1991/2008). Though this act of bringing strangeness to the target text may not be the norm in the target language, it can insist on the importance of the source text (Venuti, 1996). It is also the case for acronyms and initials. For example, in English, "WHO" can be used for "World Health Organization" but in French it is "OMS" or in English it is "UNO" but in French it is "ONU". However, for the mentioned case, Hervey and Higgins (2002) believe that using the French acronym in an English translation will certainly bring about ambiguity for the target text readers; therefore, it is better to use the equivalent in the translation for overcoming this kind of ambiguity.

Hervey and Higgins (2002) state that there remains a third option for the translators while rendering nouns. It is cultural transplantation. Here, original nouns will be substituted by local target language nouns which have related "cultural connotations" to those of the ST nouns, but, they are not their "conventional or literal equivalents" (p. 33). They exemplify some cultural transplantation of nouns in the Harry Potter translations into French: "Ravenclaw > Serdaigle, Hufflepuff $>$ Poufsouffle, Scabbers > Croûtard", and "Neville Longbottom > Neville Londubat" (p. 33). Nonetheless, translators did not alter most of the English nouns in the French translations of Harry Potter. This combination of English and French nouns brings strangeness to the target text, however, in the fantasy created world of the author, this issue may not seem odd to the target readers (Hervey \& Higgins, 2002).

According to Nord (2003), proper nouns are "mono-referential" comparing generic nouns, though they are absolutely not "mono-functional" (p. 3). Accordingly, the chief purpose of proper nouns is identifying an entity. 
Indeed, proper nouns are certainly informative. In other words, knowing the underlying culture, one may, for example, recognize masculinity or femininity of a person. A name often tells us about the age of the person or they may also inform us about the place that the person is from. Sometimes, translators need to use a generic noun with the name, e.g., Lake Urmia or Mount Damavand. Nord states that if the name is not known by the target readers, it can be problematic in translation; therefore, a generic noun should be used with the name to identify it for the readers of the target text. She (1997) proposes the functionality or the well-known term, i.e., skopos of translation and states that target text should have the same effect on its readers as the source text has on its readers. Thus, it is important that translators as cultural mediators connect the two cultures to cover the existing gaps between TT and ST.

Translation is a task which is performed in a specific cultural context (Särkkä, 2007). Many factors can affect the strategies that should be used in translating proper nouns. Extra-linguistic parameters or communicative conditions cause particular limitations on the translator's choice of strategy. For example, a proper name may have some implications; this fact can have a direct effect on the translator. In this case, he may use a special kind of strategy. Considering the aforesaid issues, Särkkä believes that in translation, proper nouns are coped with differently. A proper name may be transmitted into the target text completely without any change. This process has been conventionally called as transliteration. A proper name may be changed to match with the graphic and phonetic conventions of the target language. A proper name may be partially transmitted and partially translated. A proper name may be substituted with a different name in the target language. And finally, a proper name may also be omitted totally. These are the processes that a proper name may go through in the course of translation.

Särkkä (2007) states that local nouns like local institutional nouns may not usually identify the country. Since this fact might be missed in the translation, the translators should insert the needed adjective to present the hidden information, e.g., the Malaysian Ringgit or the US Dollar. There are also cases that the name is a famous name in the source culture but the target text readers are not familiar with them. Here, the translators may provide their readers an explanation. For example, a translator may add an explanatory comment like Anushiravan (a famous Persian king) or Piroozi (a renowned Iranian soccer team). They do not possibly mean to many target text readers. However, when the name has international fame, there is no need for such additions, e.g., the Harvard or the Louvre.

Meyer (2008) states that utilizing proper nouns shows one's knowledge of "single entities" like personal names such as "John Doe", names of places like "Hamburg", names of institutions like "the United Nations", and names of vehicles such as "Queen Mary II" (p. 107). Despite the fact that knowledge about proper nouns are very particular, most of the proper nouns, in fact, include general information. For instance, personal names normally determine gender, or place names usually tell something about the place like a country, a sea, a town, a street, etc. Institutional names normally contain "appellative constituents (World Health Organization)" that describe the aims and principles of the institution (p. 107); therefore, they facilitate communication though the reader may not be familiar with institution. Thus, proper nouns indicate various accessibility levels and their translation needs specific information. In his study, Meyer identifies five kinds of strategies regarding translating proper nouns: 1) Proper nouns are transferred into the target text, occasionally with minimum phonetic adaptations, 2) Proper nouns are not translated and removed completely, 3) Proper nouns are substituted by pronouns referring to past incidents, 4) Proper nouns are substituted with generic nouns, that is, super-ordinate nouns, 5) Proper nouns are transferred and some explanatory comments are given for increasing the accessibility for the readers. In line with him, Morarasu (2006) investigates translation of proper nouns in Dickensian novels and states that the norm of rendering proper nouns in Dickens is persevering the main characters' names. She believes that changing these personal names will change the entire titles of the books; however, the translators might sometimes transliterate the first names.

\section{Method}

Twenty Four lyrics of Hafez have been chosen randomly by the researchers as the source text of the present study and its English translation by Pazargadi (2003) as the target text. The researchers have investigated the strategies applied by the translator in rendering proper nouns. For doing so, each extracted proper noun of the source text was compared with its counterpart in the target text. Then, it has been put in the relevant translation category. The category which the researchers have applied in this study has been discussed in the following section.

\subsection{Theoretical Framework}

In the Present study, the categorization proposed by Vermes (2003) has been adapted. Vermes states that the strategies that the translators may use to render proper nouns can be categorized into the following processes: 
Transference, Translation, Substitution and Modification (pp. 93-94). In present study, we have added the next processes to them as well: omission, addition, generalization, and transference plus phonetic adaptation.

1) Transference is the strategy using which the translator makes use of the source text proper noun without applying any changes in the target languages (Vermes, 2003). In line with it, Newmark (1988, p. 81) mentions that transference is" the process of transferring a SL word to a TL text as a translation procedure". For example, the name [jæmshid] in Persian is transferred into English as Jamshid without any changes.

2) When the translator uses the conventional correspondent of the source language noun in the target language, the process is called substitution (Vermes, 2003). This strategy can be used for most of the geographical nouns. Seemingly, using the conventional equivalent (in an existing case) is the translator subconscious choice. Vermes believes that translators are usually forced to utilize the conventional form in the target text e.g. using "Hungarian Anglia for English England" (p. 93) or using Persian [Mæjärestän] for English Hungary or using Persian [Læhestän] for English Poland. Moreover, situations in which the translator uses the source text name but with graphic changes in the target text are considered to be cases of substitution. Here, the target language "form makes explicit the phonological value" of the source language noun (p. 94). This is done because languages may have different graphological conventions, e.g., "Hungarian Csingacsguk for English Chingachgook" (p. 94). However, it is not applicable to this study as Persian and English have totally different graphological conventions; therefore, all the strategies used by the translators can be regarded as substitution though they may be translation, transference and so forth. Because of this reason, graphological changes with the same phonology, i.e., transliteration, are not regarded as substitution in the present study.

3) Translation strategy is used when the noun is rendered in the target text by the translator (Vermes, 2003). Accordingly, Newmark $(1988$, p. 5) states that "rendering the meaning of a text into another language in the way that the author intended the text" is called translation. Translators use this strategy to render the original noun or part of it in the target text, for example, the last name or the first name; they use a name in the target text with the same or nearly the same connotations, e.g., Persian [Säghi] is rendered to cup-bearer in English.

4) Modification is the strategy of using a substitute in the target text for the original noun which is not related or just partly related to the source language noun conventions or logics (Vermes, 2003). It brings a considerable change in form or connotations in the target text, e.g., English "Winnie-the-Pooh" is rendered in the Hungarian as "Micimackó" (p. 94). The following case is also regarded as modification: when the translator does not use the target text correspondent and uses a different noun. For instance, "Maris" in Hungarian is normally related to maidservants and translated into English as "Rosie" (p. 94). It is not the same name or the correspondent but it has related contextual connotations. Vermes considers modification as a general term that includes omission, addition and generalization in itself. However, in the present study, omission, addition, and generalization are not regarded as sub-sects of modification but as separate translation strategies in rendering nouns.

5) Omission is the strategy where the translator substitutes the SL noun or part of it with none in the TL. In other words, the translator simply removes the original noun or part of the noun in the translation due to different reasons. He may think that it is not important or it may cause ambiguity for the TT readers or he may follow the omission strategy for other factors. For example, Abdul-Qadir Gilani in Persian may be translated into English as Abdul-Qadir where Gilani has been deleted.

6) Addition is the strategy in which the translator will use expansion in the translation of the source language noun. He can use this addition in main body of the target text or as marginal notes. Addition is used for different reasons such as giving the readers more information or eliminating the ambiguities for the readers. For example, in translating the Persian name Kashaf Rood which is the name of a river, the translator may render it this way Kashaf Rood river to give his readers more information regarding the SL noun. He can also give some explanation regarding the original nouns in the target text in terms of marginal notes. There are cases where the TL does not have the SL noun due to cultural differences and the translator, instead of using transference, uses paraphrase strategy or descriptive substitute coping with that noun; we also consider these cases as addition strategy.

7) Generalization is a strategy where the translator uses a super-ordinate noun instead of using the source language noun. For example, a translator may use a super-ordinate noun for a bicycle or a car; in this case, he can use $a$ vehicle which is a super-ordinate noun for a car or a bicycle.

8) Transference plus phonetic adaptation is the strategy that can be applied by the translators for translating proper nouns. This is the case that translators transfer the source text name into the target text but with phonetic adaptations so as to match it with the TL conventions. For example, English name Smith is transferred into Persian as [esmit] with a different phonetic pattern so as to be matched with Persian language phonological 
conventions. In fact, this strategy has not been considered as a translation process in the categorization mentioned by Vermes (2003). In the following figure, the whole strategies can be seen.

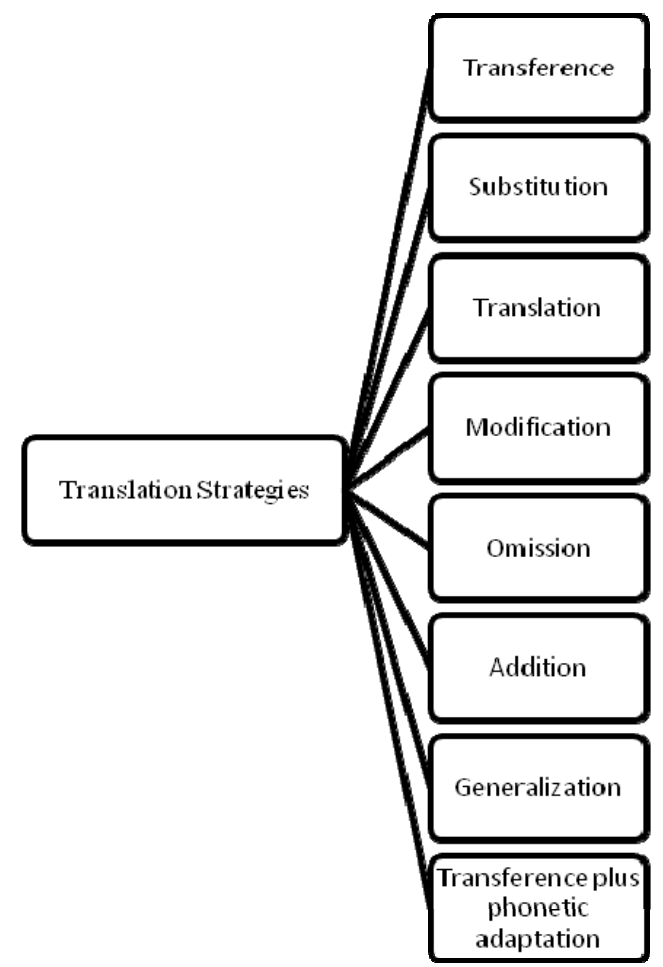

Figure 1. Translation strategies in rendering proper nouns adapted from Vermes (2003)

In line with Vermes, we also believe that modification, omission and addition strategies are used by the translators to produce the same effect on the target text readers. However, it should be mentioned that all the above seven strategies are not totally separate. They can occur simultaneously. In other words, in the process of translating a source text name into the target text, some strategies may be used. For instance, in a text, a translator might render the Persian name [Jæläl Äle-Æhmæd] as Ale-Ahmad street where he used transference, omission and addition at the same time. He omitted Jalal and transferred Ale-Ahmad and added street in his translation.

\section{Analysis of Findings}

In this section, some examples of the strategies used by the translator have been given.

\subsection{Transference Strategy}

In this strategy, the translator only transfers the noun into the target language without applying any changes. Having counted all the proper nouns that have been transferred, it has been noticed that this procedure has been occurred forty eight times. Some of these nouns are presented in Table 1.

Table 1. Transference of proper nouns

\begin{tabular}{lll}
\hline ST name & [jæmshid] & [rostæm] \\
TT name & Jamshid & Rostam \\
ST name & [äsef] & [hæsæn] \\
TT name & Asef & Hasan \\
ST name & [sufi] & {$[$ shiräz] } \\
TT name & Sufi & Shiraz \\
ST name & {$[$ hätæm $]$} & [esfehän $]$ \\
TT name & Hatam & Esfehan \\
\hline
\end{tabular}




\subsection{Substitution Strategy}

Substitution happens when the conventional equivalent of the SL noun is used in the target text. There are twenty proper nouns in the original Persian text which have been substituted in the target text by the translator. Since English has conventional counterpart for these nouns, they are substituted by the translator. Some of the proper nouns that are included in this category can be seen in Table 2 .

Table 2. Substitution of proper nouns

\begin{tabular}{lll}
\hline ST name & [khezr] & [pärsi] \\
TT name & Elias & Persian \\
ST name & [ghärun] & [eesä] \\
TT name & Korah & Jesus \\
ST name & [soleimän] & [gheisær] \\
TT name & Solomon & Caesar \\
\hline
\end{tabular}

\subsection{Translation Strategy}

This section deals with the proper nouns that are rendered in the target text by the translator. There are forty proper nouns that have been translated in the target text. Some instances of these nouns are given in Table 3.

Table 3. Translation of proper nouns

\begin{tabular}{ll}
\hline ST name & [sæbä] \\
TT name & Morning breeze \\
ST name & [golzär] \\
TT name & rose-garden \\
ST name & [mæjnun] \\
TT name & Mad \\
ST name & [säghi] \\
TT name & cup-bearer \\
\hline
\end{tabular}

\subsection{Modification Strategy}

This strategy occurs when the translator changes the form or implications of the SL noun considerably in the target text. As a whole, three proper nouns have been modified in the translation. Some examples of them are put in Table 4.

Table 4. Modification of proper nouns

\begin{tabular}{lll}
\hline ST name & [negär & [ruhäniyun] \\
TT name & idol & souls \\
\hline
\end{tabular}

\subsection{Omission Strategy}

This section deals with the source text proper nouns that are omitted in the target text. There are two nouns that have been omitted in the translation. They can be seen in the Table 5 .

Table 5. Omission of proper nouns

\begin{tabular}{lll}
\hline ST name & [tubä] & [täi $]$ \\
TT name & $\varnothing$ & $\varnothing$ \\
\hline
\end{tabular}




\subsection{Addition Strategy}

Translators may sometimes use addition in translating the original proper nouns. It has been noted that this category includes thirty one examples; some of them are given in Table 6.

Table 6. Addition of proper nouns

\begin{tabular}{ll}
\hline ST name & [kävus] \\
TT name & a fabulous king of ancient Iran \\
ST name & [khojænd] \\
TT name & a city in Turkestan of Asia \\
\hline
\end{tabular}

\subsection{Generalization Strategy}

This section deals with nouns that are substituted with super-ordinate nouns. There are three cases of the usage of generalization strategy. Some of them are presented in the Table 7.

Table 7. Generalization of proper nouns

\begin{tabular}{ll}
\hline ST name & [dey] \\
TT name & winter \\
ST name & [chægæl] \\
TT name & Turkish \\
\hline
\end{tabular}

\subsection{Transference plus Phonetic Adaptation Strategy}

This strategy occurs when the translator adapts the noun phonologically to follow the conventions of the target language. It has been noticed that this category includes seven examples. Some of them are put in Table 8.

Table 8. Transference plus phonetic adaptation of proper nouns

\begin{tabular}{ll}
\hline ST name & [ghælændær] \\
TT name & Calender \\
ST name & [solæymi] \\
TT name & Salayema \\
\hline
\end{tabular}

Summing up all translation strategies applied by Pazargadi, the results can be seen in Figure 2 . 


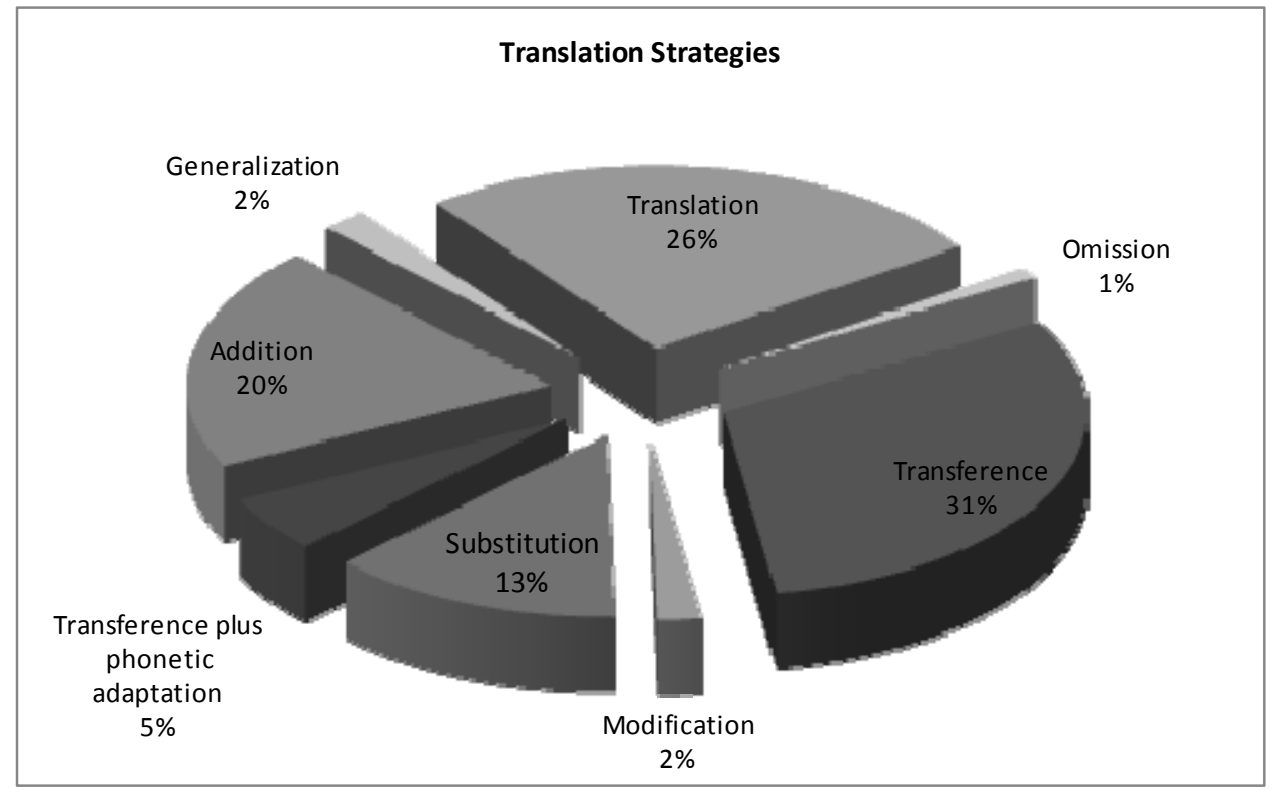

Figure 2. Translating strategies used by Pazargadi

The figure indicates that Pazargadi has used transference as the most frequent procedure in his target text. It includes 31 percent of the proper nouns. Translation strategy is in the next rank with 26 percent. Addition strategy has been used by the translator. It comprises 20 percent of the nouns. The translator has used substitution strategy in his translation which is 13 percent. Transference plus phonetic adaptations includes 5 percent of the whole proper nouns. Modification and generalization strategies have been applied both with 2 percent by the translator. Finally, omission strategy is the rarest of all the strategies since it includes only 1 percent of all proper nouns.

\section{Concluding Remarks}

In the cases that the translator has felt that the source text nouns have not specific meanings or their transference does not cause any difficulties for the readers, he preferred to transfer the nouns. Moreover, there were cases that the original nouns had some implications or connotations where the translator transfer the nouns but add some additions to his translation as well so as to explain the hidden implications of the nouns. In the cases that simple transference of the source text nouns brings difficulties for the readers or they were not according to the target text conventions the translator has phonologically adapted the nouns. In some cases that target text had conventional equivalents for the source text nouns, the translator substitute them; there were some cases that the transference of the nouns were not meaningful for the readers; thus, the translator has translated them into the target text. As changing or distortion of the source text proper nouns may bring about a totally different meaning with the one that the original author intended, modification strategy has been used quite rarely. The study shows also that there were cases that the nouns in the target text did not have meaning; thus, the translator has used more general terms or super-ordinate nouns for those nouns; by doing so, the translator tried to communicate the intended meaning by the author. Omission can be said to be the last choice for the translators. In this study, it has been seen as well that the translator only used this strategy two times where he did not omit the whole noun but part of the noun.

Generally, it should be mentioned that the translation of proper nouns for the translators is a challenging act. It is very hard for translators to understand all the author's intentions behind using each noun in the source text. Accordingly, producing identical text with the original one is not purely possible. Sometimes, the translation cannot have the same effect on the target text readers as the original text does. Though it is hard to produce the same function in the target text, the present study showed that the translator of Hafez's lyrics has tried to convey the meaning as far as possible. Moreover, in the cases that he felt the target text readers may need some extra information regarding the noun, he has used addition strategy to remove the possible ambiguities.

\section{References}

Bachman, L. F. (1990). Fundamental considerations in language testing. Oxford: Oxford University Press. 
Hatim, B., \& Mason, I. (1990). Discourse and the translator, language in social life series. London: Longman.

Hervey, S., \& Higgins, I. (2002). Thinking French translation, a course in translation method: French to English (2nd ed.). London/New York: Routledge.

Katan, D. (1999). Translating cultures: An investigation for translators, interpreters and mediators. Manchester: St. Jerome Publishing.

Meyer, B. (2008). Interpreting proper names: Different interventions in simultaneous and consecutive interpreting? Trans-kom, 1(1), 105-122.

Morarasu, N. N. (2006). Challenges in translating proper names from Dickensian novels. In F. Popescu (coord.), Translation Studies: Retrospective and Prospective Views, International Conference (pp. 97-110). Galați: Editura Fundației Universitare Dunărea de Jos.

Newmark, P. (1988). A textbook of translation. London/New York: Prentice Hall.

Newmark, P. (1993). Paragraphs on translation. Clevedon/Philadelphia/Adelaide: Multilingual Matters Ltd.

Nord, C. (1997). Translating as a purposeful activity. Functionalist approaches explained. Manchester: St. Jerome.

Nord, C. (2003). Proper names in translations for children: Alice in wonderland as a case in point. Meta: Translators' Journal, 48(1-2), 182-196. http://dx.doi.org/10.7202/006966ar

Pazargadi, A. (2003). The poems of Khaje Hafez Shirazi. Tehran: Rahnama Publication.

Sanaty Pour, B. (2009). How to translate personal names. Translation Journal, 13(4). Retrieved from http://translationjournal.net/journal/50proper.htm

Särkkä, H. (2007). Translation of proper names in non-fiction texts. Translation Journal, 11(1). Retrieved from $\mathrm{http} / / /$ translationjournal.net/journal/39proper.htm

Venuti, L. (1991). Genealogies of translation theory: Schleiermacher. TTR: Traduction, terminologie, rédaction, 4(2), 125-150. http://dx.doi.org/10.7202/037096ar

Venuti, L. (1996). Translation, heterogeneity, linguistic. TTR: Traduction, terminologie, rédaction, 9(1), 91-115. http://dx.doi.org/10.7202/037240ar

Venuti, L. (1998/2001). Strategies of translation. In M. Baker (Ed.), Routledge encyclopedia of translation studies (pp. 240-244). London/New York: Routledge.

Venuti, L. (2008). The translator's invisibility: A history of translation (2nd ed.). London: Routledge.

Vermes, A. P. (2003). Proper names in translation: An explanatory attempt. Across Languages and Cultures, 4(1), 89-108. http://dx.doi.org/10.1556/Acr.4.2003.1.5

\section{Copyrights}

Copyright for this article is retained by the author(s), with first publication rights granted to the journal.

This is an open-access article distributed under the terms and conditions of the Creative Commons Attribution license (http://creativecommons.org/licenses/by/3.0/). 